\title{
A arte da Ironia e o Novo Testamento
}

\section{The art of irony and the New Testament}

\section{El arte de la ironía y el Nuevo Testamento}

\section{Antonio Carlos Soares Santos}

\author{
A ironia não é apenas alguma coisa que acontece; \\ é alguma coisa que pelo menos pode ser representada \\ acontecendo (MUECKE, 1995, p. 91).
}

\begin{abstract}
RESUMO
A Ironia, muitas vezes, utiliza-se do eufemismo e exagero para transmitir a mensagem. É possível a Bíblia se utilizar de um recurso tão informal? Imaginar um texto dito sagrado com composições irônicas, para alguns, é inimaginável. Porém, um dos grandes avanços na crítica literária bíblica tem sido a descoberta do uso generalizado de recursos, entre esses a ironia, como estratégia comunicativa. Douglas Colin Muecke é o referencial teórico para que possamos analisar dois textos do Novo Testamento através de seus conceitos sobre o uso da Ironia como recurso literário.

Palavras-chaves: Literatura; ironia; cristianismo.
\end{abstract}

\begin{abstract}
Irony often uses euphemism and exaggeration to convey the message. Is it possible for the Bible to use such an informal resource? To imagine a so-called sacred text with ironic compositions, for some, is unimaginable. However, one of the great advances in biblical literary criticism has been the discovery of the widespread use of resources, among them irony, as communicative strategy. Douglas Colin Muecke is the theoretical reference so that we can analyze two New Testament texts through his concepts about the use of Irony as a literary resource.
\end{abstract}

Keywords: Literature; irony; Christianity.

\section{RESUMEN}

La ironía a menudo se utiliza del eufemismo y exagero para transmitir el mensaje. ¿Es posible la Biblia utilizar un recurso tan informal? Imaginar un texto dicho sagrado con composiciones irónicas, para algunos, es inimaginable. Pero uno de los grandes avances en la crítica literaria bíblica ha sido el descubrimiento del uso generalizado de recursos, entre ellos la ironía, como estrategia comunicativa. Douglas Colin Muecke es el referencial teórico para que podamos analizar dos textos del Nuevo Testamento a través de sus conceptos sobre el uso de la ironía como recurso literario.

Palabras claves: Literatura; ironía; cristianismo.

* UMESP. Graduação em Teologia pela UMESP e Mestrado em Ciência da Religião na linha de pesquisa Linbguagem e Literatura do Mundo Bíblico. kal2s@hotmail.com . 


\section{Sobre os conceitos}

O conceito de ironia não é único. Há probabilidades de apreciação em nível histórico, apontando as eras da ironia, como, por exemplo, a ironia grega (incluindo ironia socrática e ironia trágica); ironia romântica (com variados nomes do pensamento alemão do século XVIII); e ironia moderna, através de uma série de revisões sobre a própria literatura, contada a partir do Romantismo. Há, também, a probabilidade de uma crítica em nível funcional, se entendermos a ironia como emprego da retórica ou como estilo perante a própria arte, ou até mesmo a ironia como núcleo das discussões de aproximação a esta mesma arte. O que nos leva à reflexão sobre o problema que perpassa a pesquisa da ironia é saber como devemos caminhar em relação à sua análise.

Uma mudança num ponto do sistema (e tal mudança já pode ter ocorrido) poderia eventualmente levar à descoberta de que o conceito de ironia, tal como é entendido atualmente, evita-nos de encarar a literatura de uma maneira nova: não é inconcebível que a "ironia", ora um conceito-chave na crítica literária, acompanhará ao ostracismo o conceito de "sublimidade", tão indispensável aos séculos passados (MUECKE, 1995, p. 27-28).

Douglas Colin Muecke coloca, em termos literários, a ironia como um conceito sublime, que caiu no esquecimento na aplicação da crítica literária. Segundo ele, a ironia pode recompor o equilíbrio da vida quando ela está sendo levada muito a sério, ou, ao contrário, quando a vida não é levada profundamente a sério, “estabilizando o instável, mas, também, desestabilizando o excessivamente estável” (1995, p.19).

Conceituar o termo “ironia” não é uma tarefa fácil. É uma expressão que sofre com as mudanças periódicas, por ser uma palavra que foi incansavelmente usada através do tempo e da história. Assim,

A palavra ironia não quer dizer agora apenas o que significava nos séculos anteriores, não quer dizer num país tudo o que pode significar em outro, tampouco na rua o que pode significar na sala de estudos, nem para um estudioso o que pode querer dizer para outro. Os diferentes fenômenos a que se aplica a palavra podem parecer ter uma relação muito fraca. [...] Assim, o conceito de ironia a qualquer tempo é comparável a um barco ancorado que o vento e a corrente, forças variáveis e constantes, arrastam lentamente para longe de seu ancoradouro. (MUECKE ,1995, p.22)

Muecke leva ao entendimento de que cada pesquisador, cada conceituador, acompanha as direções que lhe são mais apropriadas acerca da ironia, segundo o local e o momento histórico em que está inserido e de acordo com seu conhecimento de mundo. Para melhor compreender o conceito de Muecke, é importante tomar emprestadas duas grandes categorias da ironia apresentada por ele: 
1. A ironia situacional ou observável, que corresponde justamente a coisas vistas ou apresentadas como irônicas;

[...] a situação básica metafisicamente irônica do ser humano é que ele é um ser finito que luta para compreender uma realidade infinita, portanto, incompreensível. A isto podemos chamar de ironia observável da natureza, que tem o ser humano como vítima. (1995, p.39)

2. A ironia verbal ou instrumental, por sua vez, ocorre quando há uma inversão semântica e, nesse caso, a ironia constitui em dizer uma coisa para significar outra, "como uma forma de elogiar a fim de censurar e censurar a fim de elogiar ..." (Muecke, 1995, p.33). Nesse tipo de manifestação da ironia, temos um sujeito sendo irônico; logo, trata-se, em certa medida, de um modo de comportamento.

Ou seja, diante da ironia observável, tem-se uma situação ou uma cena que deve ser percebida pelo observador e julgada irônica, não existindo, assim, “alguém sendo irônico". Já na ironia verbal, há uma atitude irônica expressa por um sujeito, que faz uso de uma inversão semântica para transmitir sua mensagem.

Destacamos que Muecke faz uma diferenciação entre ironia, paródia e sarcasmo (1995, 24-26). Para Muecke, ironia seria um modo particular de expressão que dá às palavras um oposto de seu significado ou um sentido diferente da forma literal, mantendo uma realidade que é usada para criticar ou destacar. Já paródia é uma composição que indica um estilo a uma obra, acentuando os personagens caricaturados ou de maneira ridícula. Sarcasmo, para Muecke, seria uma amarga ironia, usada contra alguém, motivado pela animosidade e insatisfação, com intenção de ferir o objeto de desprezo.

O que parece ser indicado, quando se refere à ironia, é o contraste que existe entre a aparência e a realidade. É isso que demonstra ser o traço básico de toda ironia. Kierkegaard (1991, p.11), define que "a ironia trabalha com o mal-entendido", o que seria nada mais que o encontro entre a realidade e suas possíveis interpretações.

\section{Sobre ironia e Novo Testamento}

Desde a antiguidade, a ironia, como recurso de linguagem e retórica, se faz presente na literatura. Kierkegaard viu em Sócrates a primeira reprodução aberta da ironia, comentando que, comparativamente a Cristo - quem o evangelho de João afirma ser o verbo encarnado que habitou entre nós -, Sócrates seria a encarnação da ironia que habitou entre nós (1991). Segundo Bakhtin (2013), a dualidade entre o sério e o cômico já existia nas sociedades 
primitivas. A ironia, desde muito, servia como um instrumento de subversão e desafio. A reversão dos papéis sociais é uma das formas da fala irônica, caso em que o irônico assume a posição do ironizado, criticando ou atribuindo-lhe feitos antes praticados por quem ironiza (BAKHTIN, 1999, p 265-267). Outra variação de papéis ocorre, quando se inverte - de uma forma dissimulada - a circunstância moral e ética de uma personagem: o inocente torna-se culpado, o vencedor vira o vencido. A hipérbole contribui, da mesma forma, com os procedimentos irônicos, designando e expandindo uma diferença grotesca que beira ao absurdo.

Ao olhar para o Novo Testamento, pode-se encontrar ironias que, às vezes, desafiavam as autoridades vigentes e a realidade física.

Analisaremos duas narrativas pertencentes a escritos ditos canônicos do Novo Testamento e, partindo da definição proposta por Muecke sobre ironia, veremos como e se é possível aplica-la nos referidos textos.

\section{1. $\operatorname{Marcos} 5,1-13$}

Entrementes, chegaram à outra margem do mar, à terra dos gerasenos. Ao desembarcar, logo veio dos sepulcros, ao seu encontro, um homem possesso de espírito imundo, o qual vivia nos sepulcros, e nem mesmo com cadeias alguém podia prendê-lo; porque, tendo sido muitas vezes preso com grilhões e cadeias, as cadeias foram quebradas por ele, e os grilhões, despedaçados. E ninguém podia subjugá-lo. Andava sempre, de noite e de dia, clamando por entre os sepulcros e pelos montes, ferindo-se com pedras. Quando, de longe, viu Jesus, correu e o adorou, exclamando com alta voz: Que tenho eu contigo, Jesus, Filho do Deus Altíssimo? Conjuro-te, por Deus, que não me atormentes! Porque Jesus lhe dissera: Espírito imundo, sai desse homem! E perguntou-lhe: Qual é o teu nome? Respondeu ele: Legião é o meu nome, porque somos muitos. E rogou-lhe encarecidamente que os não mandassem para fora do país. Ora, pastava ali pelo monte uma grande manada de porcos. E os espíritos imundos rogaram a Jesus, dizendo: Manda-nos para os porcos, para que entremos neles. Jesus o permitiu. Então, saindo os espíritos imundos, entraram nos porcos; e a manada, que era cerca de dois mil, precipitou-se despenhadeiro abaixo, para dentro do mar, onde se afogaram.

O termo que chama atenção é "Legião", palavra que pode ser entendida, à primeira vista, como nome próprio, isto é, alcunha dada ao sujeito em consequência da sua condição. Como alternativa, poderíamos acompanhar a antiga sugestão da exegese clássica (como Wellhausen ou Hendriksen), para a qual "Legião" poderia ser entendida como uma resposta esperta e evasiva do bando de demônios que, falando genericamente em números, visa manter em sigilo seus nomes reais. No entanto, no primeiro século, provavelmente, a palavra "Legião" apontaria para a presença militar do Império Romano. Uma 
legião romana correspondia à unidade de seis mil homens. É curioso o uso desse termo, pois há uma sequência interessante nas ocorrências do texto.

a) Os demônios se autointitularam Legião - Uma referência à presença da ocupação romana na Palestina; "Legio" é uma palavra não encontrada no grego, mas emprestada do Latim (BULTMANN, 2011, p.224). O geraseno poderia representar o povo oprimido e "possuído" por uma força estrangeira;

b) O pedido da Legião para entrar nos porcos - Os porcos eram, no código de pureza judaica (Lv. 11,7), animais considerados impuros e impróprios para alimentação;

c) Ao "possuir" os porcos, esses se lançam pelo desfiladeiro e morrem afogados no mar - O mar, para um povo do deserto, era símbolo de todas as forças negativas que se opõem a Deus e visto como um imenso abismo povoado de monstros desconhecidos, instrumentos de morte para o ser humano, que nele se afoga. Nesse sentido, Mar está relacionado ao caos e à desordem. Lugar de morte e castigo (ALVES, 1994).

Horsley (2010) enfoca a representação de uma típica posição anticolonial, que dá um sentido irônico à cena. Ao aplicarmos as categorias de ironias propostas por Muecke, percebemos que a Ironia Situacional ou Observável se enquadra no texto. A ironia só é compreendida quando observada e julgada pelo indivíduo. O uso de uma expressão (Legio) tipicamente do Latim, idioma romano; a "possessão" de porcos, animais considerados impuros, uma forma de associar a condição do imperialismo romano às impurezas; e o "suicídio" dos porcos se lançando nas profundezas do mar, lugar de morte e castigo, parecem apontar para uma ironia sobre a ocupação romana e seu desejável fim. Principalmente quando se leva em conta o momento em que o Evangelho de Marcos estava sendo redigido (60-70 E.C), que foi uma ocasião na qual a opressão romana se intensificou na tentativa de suplantar as rebeliões que emergiam neste período.

Crossan (1994, p. 352) ressalta que é difícil não compreender ou simplesmente ignorar o simbolismo irônico encontrado na narrativa do possesso geraseno. O demônio que importuna o homem, que ao mesmo tempo é um e muitos, chamado Legião, um símbolo do poder romano, é lançado ao mar. Compreende-se este relato como o sonho de todo revolucionário judeu do primeiro século. Ressalta-se, portanto, que em seu contexto discursivo original, a narrativa desempenhava um papel explicitamente anti-imperial.

Outro texto carregado de ironia encontra-se entre as chamadas Cartas Paulinas: 


\section{I Coríntios 4, 7-14}

Porque, quem te faz diferente? E que tens tu que não tenhas recebido? E, se o recebeste, por que te glorias, como se não o houveras recebido? Já estais fartos! Já estais ricos! Sem nós reinais! E quisera reinásseis para que também nós viéssemos a reinar convosco! Porque tenho para mim que Deus, a nós, apóstolos, nos pôs por últimos, como condenados à morte; pois somos feitos espetáculo ao mundo, aos anjos, e aos homens. Nós somos loucos por amor de Cristo, e vós sábios em Cristo; nós fracos, e vós fortes; vós ilustres, e nós vis. Até esta presente hora sofremos fome, e sede, e estamos nus, e recebemos bofetadas, e não temos pousada certa. E nos afadigamos, trabalhando com nossas próprias mãos. Somos injuriados, e bendizemos; somos perseguidos, e sofremos; somos blasfemados, e rogamos; até ao presente temos chegado a ser como o lixo deste mundo, e como a escória de todos. Não escrevo estas coisas para vos envergonhar; mas vos admoesto como meus filhos amados.

O contexto que emoldura a argumentação é a discussão da legitimidade da condição de apóstolo, não apenas de Paulo, mas também de Apolo. O capítulo 4 de I Coríntios é uma argumentação de defesa de Paulo diante de acusações contra seu apostolado. A cidade de Corinto era uma cidade portuária importante e rica. Ao que parece, mesmo pertencentes a uma classe social na linha da pobreza, a comunidade cristã de Corinto, talvez levada pela importância política da cidade, também passou a se considerar exageradamente valorosa (CARREZ, 1993, p. 26-28).

A crítica desenvolvida por Paulo parte desses princípios. A ironia está na conduta dessa comunidade que, sendo pobre, simples, parecia ostentar uma realidade que, na verdade, não fazia parte de sua vida cotidiana. Ao analisar a argumentação paulina, percebe-se a simulação e a contradição como dois termos que revestem sua retórica fundamentada na ironia (CROSSAN, 2007, p. 234). Pode-se apontar, também, que há um tom de absurdo no comportamento adotado pela comunidade em Corinto. Portanto, vemos que, por meio dessa figura retórica, se diz o contrário do que se quer dar a entender, mas, embora a sua forma argumentativa seja indireta, nem por isso a sua força de persuasão é menor.

$\mathrm{Na}$ aplicação dos modelos de ironias de Muecke, o texto paulino está centrado na Ironia Verbal ou Instrumental, quando o sujeito irônico diz uma coisa que significa outra. Paulo trata o comportamento da comunidade de Corinto como uma contradição à mensagem cristã, e se utiliza desse absurdo para usar o tom irônico como argumento em que mostra o "ridículo" de tal situação. 


\section{Considerações finais}

A ironia se enquadra inteiramente numa racionalidade argumentativa ajustada não só pela rejeição dos absolutismos e dos absurdos de qualquer espécie, mas, também, admite que a ambivalência seja um traço característico de uma lógica natural do discurso.

Se a ironia é, muitas vezes, uma companheira do riso, é justamente porque rompe com o pensamento ortodoxo e obriga a expandir horizontes e probabilidades interpretativas diferentes. Ela aponta o discurso argumentativo para uma natureza plural e com possibilidades. É o oposto de uma única dimensão e desafia as convicções absolutas.

Os textos do Novo Testamento, como produto literário, abarcam a ironia como forma de argumento e subversão. As narrativas encontram, dessa forma, novas possibilidades de diálogos que levam a outras dinâmicas de interpretações diversas.

\section{Referências bibliográficas}

ALVES, Herculano. O mar na Bíblia. Revista Bíblica, n. 233, 1994.

BAKHTIN, M. A cultura popular na Idade Média e no Renascimento: o contexto de François Rabelais. São Paulo: Hucitec, 1993.

BAKHTIN, M. Questões de estilística no ensino da lingua. São Paulo: Editora 34, 2013.

BULTMANN, Rudolf. Teologia del Nuevo Testamento. Salamanca: Ediciones Sígueme, 2011.

CARREZ, Maurice. Primeira epistola aos Corintios. São Paulo: Paulinas, 1993.

CROSSAN, J.D. O Jesus histórico: a vida de um camponês judeu do Mediterrâneo. Rio de Janeiro: Imago, 1994.

CROSSAN, J.D. Em busca de Paulo: como o apóstolo de Jesus opôs o Reino de Deus ao Império Romano. São Paulo: Paulinas, 2007.

HORSLEY, R.A. Jesus e a espiral da violência: resistência judaica popular na Palestina romana. São Paulo: Paulus, 2010.

KIERKEGAARD, S.A. O conceito de Ironia constantemente referido a Sócrates. Petrópolis: Vozes, 1991.

MUECK, Douglas Colin. Ironia e Irônico. São Paulo: Perspectiva, 1995.

Submetido em: 23-6-2017

Aceito em: 27-11-2017 